\title{
Embellished Particle Swarm Optimization Algorithm for Solving Reactive Power Problem
}

\author{
Kanagasabai Lenin \\ Department of EEE, Prasad V. Potluri Siddhartha Institute of Technology \\ Kanuru, Vijayawada, Andhra Pradesh -520007 \\ e-mail: gklenin@gmail.com
}

\begin{abstract}
This paper proposes Embellished Particle Swarm Optimization (EPSO) algorithm for solving reactive power problem. The main concept of Embellished Particle Swarm Optimization is to extend the single population PSO to the interacting multi-swarm model. Through this multi-swarm cooperative approach, diversity in the whole swarm community can be upheld. Concurrently, the swarm-to-swarm mechanism drastically speeds up the swarm community to converge to the global near optimum. In order to evaluate the performance of the proposed algorithm, it has been tested in standard IEEE 57,118 bus systems and results show that Embellished Particle Swarm Optimization (EPSO) is more efficient in reducing the Real power losses when compared to other standard reported algorithms.
\end{abstract}

Keywords: reactive power, transmission loss, embellished particle swarm, optimization.

\section{Introduction}

Optimal reactive power dispatch problem is one of the difficult optimization problems in power systems. The sources of the reactive power are the generators, synchronous condensers, capacitors, static compensators and tap changing transformers. The problem that has to be solved in a reactive power optimization is to determine the required reactive generation at various locations so as to optimize the objective function. Here the reactive power dispatch problem involves best utilization of the existing generator bus voltage magnitudes, transformer tap setting and the output of reactive power sources so as to minimize the loss and to maintain voltage stability of the system. It involves a nonlinear optimization problem. Various mathematical techniques have been adopted to solve this optimal reactive power dispatch problem. These include the gradient method [1, 2], Newton method [3] and linear programming [4-7].The gradient and Newton methods suffer from the difficulty in handling inequality constraints. To apply linear programming, the input- output function is to be expressed as a set of linear functions which may lead to loss of accuracy. Recently many global optimization techniques have been proposed to solve the reactive power flow problem [8-10]. In this paper Embellished Particle Swarm Optimization (EPSO) algorithm is used for solving the reactive power problem. By using the multi-swarm cooperative approach, diversity in the entire swarm community can be maintained. While at the meantime, the colony-to-colony communication mechanism speeds up the convergence rate of global optimum .The performance of EPSO has been evaluated in standard IEEE 57,118 bus test systems and the results analysis shows that our proposed approach outperforms all approaches investigated in this paper.

\section{Objective Function}

\subsection{Active Power Loss}

The objective of the reactive power dispatch problem is to minimize the active power loss and can be written in equations as follows:

$$
\mathrm{F}=\mathrm{P}_{\mathrm{L}}=\sum_{\mathrm{k} \in \mathrm{Nbr}} \mathrm{g}_{\mathrm{k}}\left(\mathrm{V}_{\mathrm{i}}^{2}+\mathrm{V}_{\mathrm{j}}^{2}-2 \mathrm{~V}_{\mathrm{i}} \mathrm{V}_{\mathrm{j}} \cos \theta_{\mathrm{ij}}\right)
$$

where F- objective function, $\mathrm{PL}$ - power loss, gk - conductance of branch, $\mathrm{Vi}$ and $\mathrm{Vj}$ are voltages at buses $\mathrm{i}, \mathrm{j}$, Nbr- total number of transmission lines in power systems. 


\subsection{Voltage Profile Improvement}

To minimize the voltage deviation in $P Q$ buses, the objective function $(F)$ can be written as:

$$
\mathrm{F}=\mathrm{P}_{\mathrm{L}}+\omega_{\mathrm{V}} \times \mathrm{VD}
$$

where VD - voltage deviation, $\omega_{\mathrm{v}}$ - is a weighting factor of voltage deviation.

And the Voltage deviation given by:

$$
\mathrm{VD}=\sum_{\mathrm{i}=1}^{\mathrm{Npq}}\left|\mathrm{V}_{\mathrm{i}}-1\right|
$$

where Npq- number of load buses

\subsection{Equality Constraint}

The equality constraint of the problem is indicated by the power balance equation as follows:

$$
\mathrm{P}_{\mathrm{G}}=\mathrm{P}_{\mathrm{D}}+\mathrm{P}_{\mathrm{L}}
$$

where PG- total power generation, PD - total power demand.

\subsection{Inequality Constraints}

The inequality constraint implies the limits on components in the power system in addition to the limits created to make sure system security. Upper and lower bounds on the active power of slack bus $(\mathrm{Pg})$, and reactive power of generators $(\mathrm{Qg})$ are written as follows:

$$
\begin{aligned}
& \mathrm{P}_{\text {gslack }}^{\min } \leq \mathrm{P}_{\text {gslack }} \leq \mathrm{P}_{\text {gslack }}^{\max } \\
& \mathrm{Q}_{\mathrm{gi}}^{\min } \leq \mathrm{Q}_{\mathrm{gi}} \leq \mathrm{Q}_{\mathrm{gi}}^{\max }, \mathrm{i} \in \mathrm{N}_{\mathrm{g}}
\end{aligned}
$$

Upper and lower bounds on the bus voltage magnitudes (Vi) is given by:

$$
\mathrm{V}_{\mathrm{i}}^{\min } \leq \mathrm{V}_{\mathrm{i}} \leq \mathrm{V}_{\mathrm{i}}^{\max }, \mathrm{i} \in \mathrm{N}
$$

Upper and lower bounds on the transformers tap ratios (Ti) is given by:

$$
\mathrm{T}_{\mathrm{i}}^{\min } \leq \mathrm{T}_{\mathrm{i}} \leq \mathrm{T}_{\mathrm{i}}^{\max }, \mathrm{i} \in \mathrm{N}_{\mathrm{T}}
$$

Upper and lower bounds on the compensators (Qc) is given by:

$$
Q_{c}^{\min } \leq Q_{c} \leq Q_{C}^{\max }, i \in N_{C}
$$

where $\mathrm{N}$ is the total number of buses, $\mathrm{Ng}$ is the total number of generators, $\mathrm{NT}$ is the total number of Transformers, $\mathrm{Nc}$ is the total number of shunt reactive compensators.

\section{Particle Swarm Optimization Algorithm (PSO)}

Particle Swarm Optimization Algorithm (PSO) is a population based optimization tool [11-19], where the system is initialized with a population of random particles and the algorithm searches for optima by updating generations. Suppose that the search space is D-dimensional. The position of the $\mathrm{i}$-th particle can be represented by a D-dimensional vector $\mathrm{X}_{\mathrm{i}}=\left(\mathrm{x}_{\mathrm{i} 1}, \mathrm{x}_{\mathrm{i} 2}, \ldots, \mathrm{x}_{\mathrm{iD}}\right)$ and the velocity of this particle is $\mathrm{V}_{\mathrm{i}}=\left(\mathrm{v}_{\mathrm{i} 1}, \mathrm{v}_{\mathrm{i} 2}, \ldots, \mathrm{v}_{\mathrm{iD}}\right)$. The best previously visited position of the $\mathrm{i}$-th particle is represented by $\mathrm{P}_{\mathrm{i}}=\left(\mathrm{p}_{\mathrm{i} 1}, \mathrm{p}_{\mathrm{i} 2}, \ldots, \mathrm{p}_{\mathrm{iD}}\right)$ and the global best position of the swarm found so far is denoted by $P_{g}=\left(p_{g 1}, p_{g 2}, \ldots, p_{g D}\right)$. The fitness of each particle can be evaluated through putting its position into a designated objective function. The particle's velocity and its new position are updated as follows: 


$$
\begin{aligned}
& v_{i d}^{t+1}=\omega^{t} v_{i d}^{t}+c_{1} r_{1}^{t}\left(p_{i d}^{t}-x_{i d}^{t}\right)+c_{2} r_{2}^{t}\left(p_{g d}^{t}-x_{i d}^{t}\right) \\
& x_{i d}^{t+1}=x_{i d}^{t}+v_{i d}^{t+1}
\end{aligned}
$$

where $d \in\{1,2, \ldots, D\}, i \in\{1,2, \ldots, N\} N$ is the population size, the superscript $t$ denotes the iteration number, $\omega$ is the inertia weight, $r 1$ and $r 2$ are two random values in the range $[0,1], c 1$ and $\mathrm{c} 2$ are the cognitive and social scaling parameters which are positive constants.

\section{Embellished Particle Swarm Optimization Algorithm}

Embellished Particle Swarm Optimization Algorithm (EPSO) algorithm following the principle and it utilizes the concept of PSO algorithm. EPSO is a robust (it performs excellent in an unusual condition also), stochastic (selection is based on the random objective function) optimization technique based on the movement and the intelligence of swarms. EPSO algorithm follows the five basic principles of the swarm intelligence and it utilizes the concept of PSO algorithm. The five basic principles are Proximity principle (population should be able to carry out simple space and time computation), Quality principle (population should respond to the quality factors pbest and gbest), Diverse Response principle (allocation of responses between pbest and gbest should ensure the diversity of responses), Stability principle (the population should not change its behavioral mode every time when the environment changes) and Adaptability principle ( the population should adapt the changes when gbest changes). EPSO is initialized by a group of random particles. Consider each particle as a bird. After initialization the particles are sorted in a descending order. Then the sorted particles are placed into the different colonies (i.e. the entire swarm or community is divided into several colonies). Intra-SwarmCommunication is described as follows: The community consists of set of colonies. Each colony performs a local search and it finally gives one best solution. Within each colony, the individual birds having their own ideas they share their ideas with each other.

Inter-Swarm-Communication is described as follows: This can be evolved through a process of iterations. After a defined number of iterations, the information obtained is passed among the colonies and the knowledge among each colony is shared. These colonies coordinately and cooperatively work together and it provides the optimal solution. With these intra and inter-birds communication mechanisms, the birds can jump out from local optima and it quickly fly through the neighbourhood of the possible global optimum. Therefore a balance between local search and global search is attained. Through this, MC - PSO overcome the problem of Premature Convergence in the PSO algorithm. The proposed methodology includes constriction factor concept. By including the constriction factor the performance of the algorithm is improved. The process is initialized with a group of random particles P. For S-dimensional problems ( $\mathrm{S}$ variables), a bird $\mathrm{i}$ is represented as,

$$
\mathrm{X}_{\mathrm{i}}=\left(\mathrm{X}_{\mathrm{i} 1}, \mathrm{X}_{\mathrm{i} 2} \mathrm{X}_{\mathrm{i} 3}\right)
$$

Then the birds are sorted in a descending order according to their fitness. Then the entire community is divided into $m$ colonies, each containing $n$ birds (i.e. $P=m \times n$ ). In this process, the first bird goes to the first colony, the second bird goes to the second colony, bird $\mathrm{m}$ goes to the mth colony, and the bird $m+1$ goes back to the first colony. Within each colony, the birds with the best and the worst fitness are represented as $x_{b}$ and $x_{g}$, and the bird with the global fitness is represented as $\mathrm{Xg}$. Then, a process similar to PSO is applied to improve only the bird with the worst fitness not for all birds in each iteration. In each iteration, the communication is formulated as velocity (V),

$\mathrm{V}=\mathrm{x} * \mathrm{~V}+\mathrm{c}_{1} \times \operatorname{rand}() \times\left(\mathrm{x}_{\mathrm{b}}-\right.$ current position $)+\mathrm{c}_{2} \times \operatorname{rand}() \times\left(\mathrm{x}_{\mathrm{g}}-\right.$ current position $)$

where

Current position $=$ current position + velocity

$\mathrm{V}$ is the velocity,

$\mathrm{x}$ is the performance improvement factor,

is the best position found so far by the particle in the colony,

IJEEI Vol. 5, No. 3, September 2017: $192-198$ 
$\mathrm{x}_{\mathrm{b}}$ is the best position found so far by the multi-colony community.

$\mathrm{x}_{\mathrm{g}}$ is the social learning rate between the particles within each colony,

$\mathrm{c}_{1}$ is the social learning rate between different colonies,

$\mathrm{c}_{2}$ is a random number between 0 and 1 .

The term $c_{1} \times \operatorname{rand}() \times\left(x_{b}-\right.$ current position $)$ describes the cooperation between individuals of the same colony and the term $c_{2} \times \operatorname{rand}() \times\left(x_{g}-\right.$ current position $)$ describes the cooperation between different colonies in the community. Then the position of the bird with the worst fitness is represented as follows

change in bird position, $\mathrm{D}_{\mathrm{i}}=\operatorname{rand}() \times\left(\mathrm{x}_{\mathrm{b}}-\mathrm{x}_{\mathrm{w}}\right)$

new position, $\mathrm{x}_{\mathrm{w}}=$ current position $\mathrm{x}_{\mathrm{w}}+\mathrm{D}_{\mathrm{i}}$

where $D_{\max } \geq D_{i} \geq-D_{\text {max }}$, where $D_{\max }$ is the maximum allowed change in a bird'sposition

If this process produces a better solution, it replaces the worst bird, else the calculations in this equation are repeated but with respect to the global best bird $\left(x_{b}\right.$ replaces $\left.x_{g}\right)$. If no updation is possible then a new solution is randomly generated to replace that bird.

EPSO Algorithm for Reactive power optimization problem.

Begin;

Initialization:

Generate random population of $\mathrm{P}$ solutions (i particles);

For each individual $\mathrm{i} \in \mathrm{P}$;

Fitness Evaluation:

Calculate fitness (i);

Sorting:

Sort the population $\mathrm{P}$ in descending order of their fitness;

Divide the entire community $\mathrm{P}$ into $\mathrm{m}$ Colonies (Community);

Intra Colony Communication:

For each colony;

Determine the best and worst particles;

Improve the worst particle by using equations 3 and 4;

Repeat for a specific number of iterations;

Self- attraction within the colony is achieved by equation 1 in the 2 nd term;

End;

Inter Colony Communication:

Combine the evolved colonies;

Sorting: Sort the population $\mathrm{P}$ in descending order of their fitness;

Cooperation between different colonies is achieved by equation 1 in the 3rd term;

Termination:

Check if termination = true;

End;

\section{Simulation Results}

Proposed Embellished Particle Swarm Optimization (EPSO) algorithm is tested in standard IEEE-57 bus power system. The reactive power compensation buses are 18, 25 and 53. Bus 2, 3, 6, 8, 9 and 12 are PV buses and bus 1 is selected as slack-bus. The system variable limits are given in Table 1.

The preliminary conditions for the IEEE-57 bus power system are given as follows:

Pload = 12.018 p.u. Qload = 3.012 p.u.

The total initial generations and power losses are obtained as follows:

$\sum \mathrm{P}_{\mathrm{G}}=12.5048$ p.u. $\sum \mathrm{Q}_{\mathrm{G}}=3.3217$ p.u.

Ploss $=0.25625$ p.u. Qloss $=-1.2017$ p.u.

Table 2 shows the various system control variables i.e. generator bus voltages, shunt capacitances and transformer tap settings obtained after EPSO based optimization which are 
within the acceptable limits. In Table 3, shows the comparison of optimum results obtained from proposed EPSO with other optimization techniques. These results indicate the robustness of proposed EPSO approach for providing better optimal solution in case of IEEE-57 bus system.

Table 1. Variable limits

\begin{tabular}{cccccccc}
\hline \multicolumn{2}{c}{ Reactive Power Generation } & \multicolumn{2}{c}{$\begin{array}{c}\text { Voltage And Tap Setting } \\
\text { Limits }\end{array}$} & \multicolumn{3}{c}{ Shunt Capacitor Limits } \\
\hline Bus no & Qgmin & Qgmax & vgmin & 0.9 & Bus no & Qcmin & Qcmax \\
1 & -1.4 & 1 & Vgmax & 1.0 & 18 & 0 & 10 \\
2 & -.015 & 0.3 & vpqmin & 0.91 & 25 & 0 & 5.2 \\
3 & -.02 & 0.4 & Vpqmax & 1.05 & 53 & 0 & 6.1 \\
6 & -0.04 & 0.21 & tkmin & 0.9 & & & \\
8 & -1.3 & 1 & tkmax & 1.0 & & & \\
9 & -0.03 & 0.04 & & & & & \\
12 & -0.4 & 1.50 & & & & \\
\hline
\end{tabular}

Table 2. Control variables obtained after optimization

\begin{tabular}{cc}
\hline $\begin{array}{c}\text { Control } \\
\text { Variables }\end{array}$ & EPSO \\
\hline V1 & 1.1 \\
V2 & 1.031 \\
V3 & 1.040 \\
V6 & 1.039 \\
V8 & 1.030 \\
V9 & 1.010 \\
V12 & 1.020 \\
Qc18 & 0.0654 \\
Qc25 & 0.200 \\
Qc53 & 0.0452 \\
T4-18 & 1.010 \\
T21-20 & 1.057 \\
T24-25 & 0.871 \\
T24-26 & 0.819 \\
T7-29 & 1.051 \\
T34-32 & 0.880 \\
T11-41 & 1.021 \\
T15-45 & 1.040 \\
T14-46 & 0.910 \\
T10-51 & 1.021 \\
T13-49 & 1.060 \\
T11-43 & 0.910 \\
T40-56 & 0.900 \\
T39-57 & 0.950 \\
T9-55 & 0.950 \\
\hline & \\
\hline
\end{tabular}

Table 3. Comparison results

\begin{tabular}{clccc}
\hline S.No. & $\begin{array}{c}\text { Optimization } \\
\text { Algorithm }\end{array}$ & Finest Solution & Poorest Solution & $\begin{array}{c}\text { Normal } \\
\text { Solution }\end{array}$ \\
\hline 1 & NLP [20] & 0.25902 & 0.30854 & 0.27858 \\
2 & CGA [20] & 0.25244 & 0.27507 & 0.26293 \\
3 & AGA [20] & 0.24564 & 0.26671 & 0.25127 \\
4 & PSO-w [20] & 0.24270 & 0.26152 & 0.24725 \\
5 & PSO-cf [20] & 0.24280 & 0.26032 & 0.24698 \\
6 & CLPSO [20] & 0.24515 & 0.24780 & 0.24673 \\
7 & SPSO-07 [20] & 0.24430 & 0.25457 & 0.24752 \\
8 & L-DE [20] & 0.27812 & 0.41909 & 0.33177 \\
9 & L-SACP-DE [20] & 0.27915 & 0.36978 & 0.31032 \\
10 & L-SaDE [20] & 0.24267 & 0.24391 & 0.24311 \\
11 & SOA [20] & 0.24265 & 0.24280 & 0.24270 \\
12 & LM [21] & 0.2484 & 0.2922 & 0.2641 \\
13 & MBEP1 [21] & 0.2474 & 0.2848 & 0.2643 \\
14 & MBEP2 [21] & 0.2482 & 0.283 & 0.2592 \\
15 & BES100 [21] & 0.2438 & 0.263 & 0.2541 \\
16 & BES200 [21] & 0.3417 & 0.2486 & 0.2443 \\
17 & Proposed EPSO & 0.22107 & 0.23128 & 0.22172 \\
\hline
\end{tabular}

IJEEI Vol. 5, No. 3, September 2017: $192-198$ 
Proposed Embellished Particle Swarm Optimization (EPSO) has been tested in standard IEEE 118-bus test system [22] .The system has 54 generator buses, 64 load buses, 186 branches and 9 of them are with the tap setting transformers. The limits of voltage on generator buses are $0.95-1.1$ per-unit., and on load buses are $0.95-1.05$ per-unit. The limit of transformer rate is $0.9-1.1$, with the changes step of 0.025 . The limitations of reactive power source are listed in Table 4, with the change in step of 0.01 .

Table 4. Limitation of reactive power sources

\begin{tabular}{lccccccc}
\hline BUS & 5 & 34 & 37 & 44 & 45 & 46 & 48 \\
QCMAX & 0 & 14 & 0 & 10 & 10 & 10 & 15 \\
QCMIN & -40 & 0 & -25 & 0 & 0 & 0 & 0 \\
BUS & 74 & 79 & 82 & 83 & 105 & 107 & 110 \\
QCMAX & 12 & 20 & 20 & 10 & 20 & 6 & 6 \\
QCMIN & 0 & 0 & 0 & 0 & 0 & 0 & 0 \\
\hline
\end{tabular}

The statistical comparison results of 50 trial runs have been list in Table 5 and the results clearly show the better performance of proposed EPSO algorithm.

Table 5. Comparison Results

\begin{tabular}{lcccc}
\hline Active power loss (MW) & $\begin{array}{c}\text { BBO } \\
{[23]}\end{array}$ & $\begin{array}{c}\text { ILSBBO/ } \\
\text { strategy1 } \\
{[23]}\end{array}$ & $\begin{array}{c}\text { ILSBBO/ } \\
\text { strategy1 } \\
{[23]}\end{array}$ & $\begin{array}{c}\text { Proposed } \\
\text { EPSO }\end{array}$ \\
\hline Min & 128.77 & 126.98 & 124.78 & 115.97 \\
Max & 132.64 & 137.34 & 132.39 & 121.02 \\
Average & 130.21 & 130.37 & 129.22 & 119.52 \\
\hline
\end{tabular}

\section{Conclusion}

In this paper an innovative approach Embellished Particle Swarm Optimization (EPSO) algorithm successfully reactive power problem. Swarm-to-swarm mechanism drastically speeds up the swarm community to converge to the global near optimum. The performance of the proposed algorithm has been demonstrated by testing it on standard IEEE 57,118 test bus systems. Proposed Embellished Particle Swarm Optimization EPSO algorithm out performs other reported standard algorithm's in reducing real power loss.

\section{References}

[1] O Alsac, B Scott. Optimal load flow with steady state security. IEEE Transaction. PAS. 1973: 745-751.

[2] Lee KY, Paru YM, Oritz JL. A united approach to optimal real and reactive power dispatch. IEEE Transactions on power Apparatus and systems. 1985: 1147-1153

[3] A Monticelli, MVF Pereira, S Granville. Security constrained optimal power flow with post contingency corrective rescheduling. IEEE Transactions on Power Systems. 1987: 175-182.

[4] Deeb N, Shahidehpur SM. Linear reactive power optimization in a large power network using the decomposition approach. IEEE Transactions on power system. 1990; 5(2): 428-435.

[5] E Hobson. Network consrained reactive power control using linear programming. IEEE Transactions on power systems PAS. 1980; 99(4): 868-87.

[6] KY Lee, YM Park, JL Oritz. Fuel cost optimization for both real and reactive power dispatches. IEE Proc; (3): 85-93.

[7] MK Mangoli, KY Lee. Optimal real and reactive power control using linear programming. Electr. Power Syst.Res.1993(26): 1-10.

[8] Berizzi C, Bovo, M Merlo, M Delfanti A. GA approach to compare ORPF objective functions including secondary voltage regulation. Electric Power Systems Research. 2012; 84(1): 187-194.

[9] D Devaraj, B Yeganarayana. Genetic algorithm based optimal power flow for security enhancement. IEE proc-Generation. Transmission and. Distribution. 2005: 152.

[10] CA Canizares, ACZ de Souza, VH Quintana. Comparison of performance indices for detection of proximity to voltage collapse. 1996; 11(3): 1441-1450.

[11] J Kennedy, RC Eberhart. Particle Swarm Optimization. IEEE International Conference on Neural Networks.1995: 1942-1948. 
[12] RC Eberhart, J Kennedy. A New Optimizer Using Particle Swarm Theory. Proceedings of the 6th International Symposium on Micro Machine and Human Science. 1995: 39-43.

[13] A Ratnaweera, SK Halgamuge, HC Watson. Self-organizing hierarchical particle swarm optimizer with time-varying acceleration coefficients. IEEE Transactions on Evolutionary Computation. 2004; 8(3): 240-255.

[14] J Sun, B Feng, W Xu. Particle swarm optimization with particles having quantum behavior. in Proceedings of the IEEE Congress on Evolutionary Computation. USA. 2004: 325-331.

[15] Jing Liu, Wenbo Xu, Jun Sun. Quantum-behaved particle swarm optimization with mutation operator. Proceedings of the 17th IEEE International Conference on Tools with Artificial Intelligence Pages. 2005: 237-240.

[16] RA Krohling. Gaussian particle swarm with jumps. in Proceedings of the IEEE Congress on Evolutionary Computation. UK. 2005: 1226-1231.

[17] RA Krohling, L dos Santos Coelho. PSO-E: Particle Swarm with Exponential Distribution. in Proceedings of the IEEE Congress on Evolutionary Computation. 2006: 1428- 1433.

[18] M Clerc, J Kennedy. The Particle Swarm: Explosion, Stability and Convergence in a Multi-Dimensional Complex Space. IEEE Trans. on Evolutionary Computation. 2002; 6: 58-73.

[19] Eberchart R, Kennedy J. A new optimizer using particle swarm theory. Proceedings of the International Symposium on Micro Machine and Human Science. 1995: 39-43.

[20] Chaohua Dai, Weirong Chen, Yunfang Zhu, Xuexia Zhang. Seeker optimization algorithm for optimal reactive power dispatch. IEEE Trans. Power Systems. 2009; 24(3): 1218-1231.

[21] JR Gomes, R Saavedra. Optimal reactive power dispatch using evolutionary computation: Extended algorithms. IEE Proc.-Gener. Transm. Distrib. 1999; 146.

[22] IEEE. The IEEE 30-bus test system and the IEEE 118-test system", (1993), http://www.ee.washington.edu/trsearch/pstca/.

[23] Jiangtao Cao, Fuli Wang, Ping Li. An Improved Biogeography-based Optimization Algorithm for Optimal Reactive Power Flow. International Journal of Control and Automation. 2014; 7(3): 161-176.

IJEEI Vol. 5, No. 3, September 2017: $192-198$ 